\title{
aniki
}

Revista Portuguesa da Imagem em Movimento

Portuguese Journal of the Moving Image

\section{A paisagem no cinema: imagens para pensar o tempo através do espaço} Filipa Rosário ${ }^{1}$ e Iván Villarmea Álvarez ${ }^{2}$

No pequeno conto de Sam Shepard, "Gary Cooper or the Landscape" (1994), lê-se um diálogo entre um homem norte-americano, provavelmente o próprio Shepard, e uma mulher sueca. Conversam sobre viajar de carro nos Estados Unidos, as vistas do Oeste e aquilo que mais marca alguém que, na "longínqua e exótica" Europa, vê westerns norte-americanos:

Where did you hear about the West in Sweden?

Movies. American movies. We see that great landscape in our dreams. It haunts us.

So it's the landscape that grabs you more than the characters?

Yes. That vast background.

So in Sweden, when you're watching an American western you're all staring at the background? Is that it?

I suppose. It's so evocative to us. All that space. Sweden is very close.

So it doesn't matter who's the western - it could be John Wayne or Jerry Lewis - because everyone is really captured by the landscape? $(1996,179)$

A tensão explorada no conto entre paisagem - o "fundo" - e personagem - o agente da ação - é, em termos puramente fílmicos, aquilo que caracteriza a dinâmica da paisagem, sobretudo no cinema narrativo. Martin Lefebvre sugere que a paisagem fílmica é criada a partir do cenário, sempre que este adquire autonomia narrativa face à ação que anima o filme:

(...) When I contemplate a piece of film, I stop following the story for a moment, even if the narrative does not completely disappear from my consciousness - to which I may add that is precisely because the narrative does not disappear from my consciousness that I can easily pick it up again. The interruption of the narrative by contemplation has the effect of isolating the object of the gaze, of momentarily freeing it from its narrative function. Said differently, the contemplation of filmic spectacle

\footnotetext{
${ }^{1}$ Universidade de Lisboa, Faculdade de Letras, Centro de Estudos Comparatistas, 1600-214, Lisboa, Portugal.

${ }^{2}$ Universidade de Santiago de Compostela, Faculdade de Geografia, História e Arte, Departamento de História da Arte, 15703, Santiago de Compostela, Galiza - Espanha.
} 
depends on an "autonomising" gaze. It is this gaze which enables the notion of filmic landscape in narrative fiction (and eventbased documentary) film; it makes possible the transition from setting to landscape. $(2006,29)$

Portanto, no cinema, a paisagem surge quando a ação perde primazia narrativa, quando o cenário é apresentado através de mecanismos que potenciam a sua representação enquanto espetáculo, tendencialmente quando o realizador permite ou obriga à contemplação da imagem. A mudez das personagens, a fixidez dos seus corpos, a lentidão da cena, a música tocada em largo são alguns exemplos desses dispositivos.

A obra de James Benning é, por via do seu formalismo esquemático, tão exemplar quanto radical neste sentido: o realizador norteamericano trabalha a partir de sequências de longos enquadramentos estáticos de espaços abertos, despojados de personagens e diálogos. Com efeito, Benning especializou-se na rarefação dos temps-morts, que Barthes, a propósito do cinema de Antonioni, define como a extensão da insistência no poder do olhar por parte de todos os artistas visuais, o que quebra a convenção narrativa, e assim perturba a ordem

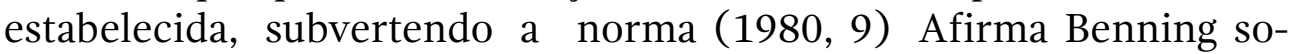
bre o movimento pendular do gaze no (seu) cinema de paisagem:

When you start to watch a smokestack scene it's obviously a smokestack and you can apply particular meanings to that, even clichéd meanings like pollution or phallic symbol - but since it's on for seven minutes and a half eventually you have to deal with it as swirling grain on screen. Near the end of the scene, however, a plane comes through, so that after you've begun to look at the image formally it's reintroduced into the narrative. $(1992,232)$

Aqui, as palavras de Benning vão ao encontro da teoria de Lefebvre, abrindo, no entanto o escopo da sua aplicação, o que comprova por via do seu próprio cinema. Não é apenas na ficção narrativa e no documentário centrado em eventos que se dá o trânsito entre o "olhar para a imagem de modo formal" - o tal olhar autonomizante que isola o objeto do gaze - e a posterior reintrodução do mesmo olhar na narrativa. Tal movimento tem lugar porque é intrínseco ao próprio processo de construção do filme, da sua significação. E esta, no que respeita ao estudo da paisagem, é primeira e necessariamente definida em função desta escala, mesmo que essa definição se torne, posteriormente, subtexto.

No seu artigo "Paisagem - Sobre a reconfiguração cinematográfica da descrição da natureza" (2014), Inês Sapeta Dias faz cruzar a História de Arte, a Filosofia e a Teoria do Cinema com a análise de alguns filmes para compreender de que forma o cinema rearticula questões teóricas concretas, que a pintura já parecia querer colocar, mesmo que de forma embrionária, desde o século XV, quando a palavra "paisagem" surge sob várias formas, um pouco por toda a Europa. 
Sobre a relação entre paisagem e pintura, escreve Anne Cauquelin:

Tomada apenas no contexto da pintura, a paisagem restituir-se-ia, pois, a uma representação figurada, destinada a seduzir a visão do espectador através da ilusão perspectivista. A inesgotável riqueza dos elementos naturais encontraria um local privilegiado, o quadro, para surgir na harmonia enquadrada de uma forma e incitaria, então, a interessar-se por todos os aspectos da Natureza, como por uma realidade à qual o quadro daria acesso. $(2008,28)$

A paisagem - palavra e conceito - surge, então, no âmbito da pintura da natureza, a revelar, por via do enquadramento, um ponto de vista autoral, e esse segmento de espaço natural encontra-se disposto na tela segundo uma ordem ditada, sobretudo, pelas regras da perspetiva. Portanto, a paisagem é, desde a sua génese, um conceito subjetivo e visual, e, por depender do olhar de quem a retrata e de quem a contempla - ou vice-versa - permite interpretações multidisciplinares daquele espaço/lugar, daquela representação de espaço/lugar. Tudo isto leva a que a paisagem se defina pela sua transdisciplinaridade.

As possibilidades de significação da paisagem no cinema são, consequentemente, tão diversas quanto os seus pontos de vista. A paisagem fílmica pode ser psicológica e alegórica, tendo em conta a possibilidade de os cenários procederem enquanto manifestações alegóricas da mente da personagem no contexto de paisagens geográficas culturalmente codificadas, como comprova David Melbye em Landscape Allegory in Cinema - From Wilderness to Wasteland (2010). A paisagem fílmica é política e cultural: Iván Villarmea Álvarez, em Documenting Cityscapes - Urban Change in Contemporary Non-Fiction Film (2015), revela-nos isso mesmo, ao mostrar como a subjetividade tem vindo a conquistar protagonismo na representação da cidade pósindustrial no documentário contemporâneo. A paisagem fílmica é também nacionalista: Cinema and Landscape (2010), editado por Graeme Harper e Jonathan R. Rayner, e, em grande parte, Landscape and Film (2006), editado por Martin Lefebvre, refletem a tendência massiva por parte da crítica especializada de procurar compreender a paisagem fílmica, individuando-a nas suas fronteiras geográficas. Num mundo globalizado, o "local" adquire maior relevância simbólica e, assim, especificidades históricas e culturais dos contextos nacionalistas tornam-se centrais no estudo da paisagem no cinema. A paisagem fílmica é também eco-crítica e cultural: editado por Anat Pick e Guinevere Narraway, Screening Nature: Cinema beyond the Human (2013) reúne textos sobre filmes onde questões de estética, política, justiça, relações entre diferentes espécies, sexualidade e género, classe, raça e ideologia, revelam a tentativa de dominação da natureza por parte da humanidade.

Esta curta mas representativa lista reflete alguns dos caminhos teóricos tomados pelos estudos sobre a paisagem no cinema. Trans- 
disciplinar e complexa, a paisagem, dentro e fora do cinema, é palimpsesto, reúne informação infinita, vai sendo reescrita, paradoxalmente, de forma linear e não-linear. Na sua geografia, ela espelha a humanidade, a cultura, o status quo, a política, a filosofia, a arte, a História. "Landscape's most crucial condition is space, but its deepest theme is time," relembra Rebecca Solnit (2002, 132). O cinema, que retrata, cria e intervém efetivamente na paisagem, permite compreender e avaliar distâncias teóricas e concretas do mundo e da linguagem, às quais de outra forma não se acede. E é nesta confluência múltipla de olhares díspares na representação da paisagem pela imagem em movimento que vemos devolvidos todos os tempos do mundo. Por isso, a principal intenção deste dossiê é, simplesmente, oferecer um novo contributo para pensar o tempo através do espaço.

As páginas seguintes apresentam diferentes abordagens conceptuais que pretendem refletir, de forma natural e complexa, a diversidade de possibilidades que existem para pensar estas relações entre paisagem e cinema de uma perspetiva histórica, estética, narrativa, filosófica e política. Neste sentido, o dossiê inclui um trabalho sobre a evolução histórica e estética do fundo, um estudo de determinadas figuras de estilo, várias análises comparativas de filmes que têm elementos formais ou temáticos em comum, e também algumas análises de caso, quer da carreira de um cineasta, quer de um único filme. Para organizar estes materiais, a disposição de artigos dentro do dossiê segue a ordem cronológica dos filmes analisados, o que significa que o primeiro texto é dedicado ao cinema da primeira metade do século XX e os dois últimos ao cinema do início do século XXI. A variedade de discursos recolhidos nestas páginas implica ainda uma necessária polifonia linguística, que permite oferecer os resultados de investigações científicas realizadas em diferentes locais do mundo, no presente, e na sua língua original, sem a demora que sempre produz o processo de tradução. Por este motivo, o dossiê inclui textos escritos nas línguas portuguesa, espanhola e inglesa que, por vezes, dialogam mesmo entre si.

O primeiro artigo, assinado pelo investigador espanhol Carlos Muguiro, trabalha sobre uma categoria estética muito específica: o fundo. O seu tema central é a evolução da posição e, sobretudo, do significado deste elemento no cinema russo e soviético - de que $\mathrm{Mu}$ guiro é grande especialista - desde os anos dez até o início dos anos quarenta do século XX. O artigo propõe, em particular, um estudo do poder simbólico do fundo como conceito organizador da paisagem cinematográfica num momento em que a conquista do território eurasiático teve o seu reflexo na conquista do fundo do enquadramento. A partir de uma filmografia de mais de trinta títulos, Muguiro estabelece um percurso, intitulado "a memória do fundo," dividido em três fases: a primeira fase, que o autor denomina "o fundo da imagem," corresponde ao cinema dos anos dez, que ainda apresentava uma forte influência da encenação teatral; a segunda fase, caracterizada pela 
ocupação do fundo, tem a ver com os filmes dos anos vinte que participam na exploração física e cinematográfica do território; e a terceira fase, por último, corresponde ao "fundo imóvel," que coincide com a generalização da estética do Realismo Socialista a partir dos anos trinta. Estas três fases pressupõem diferentes avatares da dialética entre a cultura e a natureza, dialética essa que atravessa toda a história do povo russo: permite-se, assim, conhecer a evolução do significado da paisagem no cinema russo e soviético da época.

O segundo artigo é um estudo de caso sobre a representação da paisagem portuguesa na obra do cineasta Manuel Guimarães, realizado pelo jovem investigador Tiago Vieira da Silva. Este autor chama a atenção para o caráter disruptivo de filmes neorrealistas como Saltimbancos (1951), Nazaré (1952) ou Vidas sem Rumo (1956), no âmbito das etnopaisagens habituais do cinema do Estado Novo. O motivo desta disrupção liga-se ao facto de, segundo explica Vieira da Silva, Guimarães ter subvertido a representação otimista das relações entre o povo e o território, desligando as suas imagens da paisagem portuguesa de qualquer perspetiva "romanticizante." Esta subversão prende-se, por um lado, com a renovação plástica e sensorial das representações dos territórios e comunidades que formam o imaginário nacional; e, por outro, com protagonismo que o realizador concedeu às personagens pertencentes a grupos sociais marginalizados, como os saltimbancos, os pescadores, ou os trabalhadores assalariados do Alentejo. O artigo, portanto, salienta a capacidade de Guimarães de introduzir pequenas alterações no discurso cinematográfico sobre a nação portuguesa durante as últimas décadas do Estado Novo, antes mesmo da mudança de paradigma que supôs o surgimento do Novo Cinema Português.

A simbologia psicológica da paisagem é o tema central do terceiro artigo, no qual o investigador norte-americano David Melbye dá continuidade à pesquisa desenvolvida em Landscape Allegory in Cinema (2010). Este novo texto analisa a evolução e convenções do psychological landscape film, um género caracterizado pela utilização alegórica da paisagem para expressar os sentimentos e emoções das personagens. O trabalho de Melbye descreve, neste caso, algumas das técnicas e estratégias através das quais os cineastas transformam locais naturais em projeções psicológicas de estados mentais. Independentemente do seu papel narrativo, estas paisagens funcionam como espaços do relato, exteriorizando as tensões internas dos personagens através da ressignificação do fundo. Melbye apresenta como exemplos deste género filmes que pertencem à modernidade ocidental: a sua amostra abre com alguns westerns dos anos cinquenta, como The Searchers (John Ford, 1956), para depois analisar em detalhe técnicas como a justaposição ou a sobreposição de imagens em vários filmes de finais dos anos setenta, nomeadamente The Shout (Jerzy Skolimowski, 1978), Sorcerer (William Friedkin, 1977) e Apocalypse Now (Francis Ford Coppola, 1979). Melbye lamenta o 
abandono deste género no cinema pós-moderno ocidental, pelo que termina o seu artigo com uma análise do filme coreano Seopyeonje (Im Kwon-taek, 1993), um gesto que abre a possibilidade de continuar com a sua pesquisa no cinema oriental das últimas décadas.

A investigadora brasileira Daniela Giovana Siqueira assina, por sua vez, o quarto artigo, dedicado exclusivamente à análise em profundidade de um filme pouco conhecido e estudado: a longametragem brasileira A Vida Provisória (Maurício Gomes Leite, 1968). Esta fita segue o seu protagonista por três cidades - Rio de Janeiro, Belo Horizonte e Brasília -, representadas, segundo a autora, numa dupla perspetiva autobiográfica e política: por um lado, o ofício jornalista - e o itinerário da personagem através do território reproduzem o próprio percurso profissional e vital do cineasta; e, por outro lado, o estilo do filme estabelece uma leitura sensorial e mesmo ideológica das paisagens urbanas destas cidades durante os primeiros anos da ditadura militar brasileira. $\mathrm{O}$ artigo, portanto, tem como objetivo contribuir para a discussão sobre as relações entre a cidade real, as suas representações e os discursos posteriores sobre estas cidades. O facto de considerar o filme como um documento histórico permite à autora desenvolver uma reflexão sobre o tempo através do espaço, isto é, abordar uma determinada época - a ditadura militar brasileira - através da análise das representações cinematográficas dos seus espaços urbanos.

A leitura sensorial da paisagem também está na base do quinto artigo do dossiê, no que a poeta e cineasta brasileira Ana Costa Ribeiro investiga as relações físicas e conceptuais entre o corpo, a memória e a paisagem. A sua análise comparativa dos filmes de nãoficção Ten Skies (James Benning, 2004) e Sin Peso (Cao Guimarães, 2007) salienta a importância do som e da sua associação com o corpo e com a memória no processo de construção de novas paisagens, isto é, de novas formas de relação entre as pessoas e o ambiente, a partir dos espaços e tempos que cineastas e espectadores acedem através do enquadramento e da composição. As imagens quase abstratas destes filmes são interpretadas pela autora em relação aos sons que as acompanham, atendendo especificamente à sua capacidade para estabelecer aquilo a que chama poéticas do deslocamento: entrecruzamentos espaciais e temporais dentro de um mesmo filme que expandem a nossa experiência da paisagem.

A projeção da memória dos espectadores sobre as imagens da paisagem é um dos fatores que contribuem, segundo Ribeiro, para a formação de novas paisagens. Neste sentido, o registo cinematográfico de uma determinada paisagem pode despertar uma série de lembranças no público que, depois, condicionará a sua interpretação das imagens. Consciente desta dinâmica, a investigadora argentina Irene Depetris Chauvin propõe, no sexto e último artigo do dossiê, uma análise comparativa de três trabalhos de não-ficção que apresentam distintas paisagens aquáticas como lugares de memória: a longa- 
metragem El botón de nácar (Patricio Guzmán, 2015), o vídeotríptico Los durmientes (Enrique Ramírez, 2015) e a curta-metragem Las águas del olvido (Jonathan Perel, 2013). Estes filmes exploram os sentidos contraditórios da água como fonte da vida e epicentro de culturas, mas também como cemitério para os indígenas da Patagónia e as vítimas dos voos da morte perpetrados pelas ditaduras chilena e argentina nos anos setenta e oitenta do século XX. Depetris Chauvin está especialmente interessada em estudar o discurso sobre a memória histórica destes trabalhos, que utilizam um estilo performativo e uma estética sensorial para atribuir novos significados aos imaginários aquáticos do Cone Sul. As imagens de paisagens marítimas e fluviais compõem nestes filmes uma geografia espectral, onde a água é um significante em disputa, porque é uma presença que relembra ausências.

O caráter instável destas paisagens aquáticas, sempre sujeitas a alterações e reinterpretações, é uma boa metáfora para fechar este dossiê, pois qualquer imagem em movimento de qualquer espaço real ou imaginário possui agora, desde a entrada na era digital, a mesma potencialidade e maleabilidade que uma gota de água: pode ser e significar aquilo que cineastas e espectadores queiram que seja e que signifique. Por isso, se queremos perceber o mundo através das suas imagens, devemos perceber antes os mecanismos de construção de significado dessas imagens. Esse é o trabalho de críticos e investigadores, e esse é também o objetivo deste dossiê: estabelecer a genealogia dos significados das paisagens representadas para explicar depois a sua ligação com distintas linhas do pensamento contemporâneo.

\section{BIBLIOGRAFIA}

Barthes, Roland. 1980. "Cher Antonioni." Cahiers du Cinéma 311: 911.

Benning, James. 1992. “James Benning.” In A Critical Cinema 2: Interviews with Independent Filmmakers, Scott MacDonald (ed.), 228-254. Berkeley, Los Angeles: University of California Press.

Cauquelin, Anne. 2008. A Invenção da Paisagem. Lisboa: Edições 70.

Dias, Inês Sapeta. 2014. "Paisagem - Sobre a reconfiguração cinematográfica da descrição da natureza." In Cinema e Filosofia Compêndio, João Mário Grilo e Maria Irene Aparício (eds.), 283-301. Lisboa: Edições Colibri.

Harper, Graeme e Jonathan R. Rayner (eds.). 2010. Cinema and Landscape. Bristol, Chicago: Intellect Books. 
Lefebvre, Martin. 2006. "Between Setting and Landscape in the Cinema." In Landscape and Film, Martin Lefebvre (ed.), 19-59. Nova Iorque: Routledge.

Melbye, David. 2010. Landscape Allegory in Cinema - From Wilderness to Wasteland. Nova Iorque: Palgrave Macmillan.

Narraway, Guinevere e Anat Pick (eds.). 2013. Screening Nature: Cinema beyond the Human. Oxford, Nova Iorque: Berghahn Books.

Shepard, Sam. 1996. "Gary Cooper or the Landscape." In Cruising Paradise, 178-180. Nova Iorque: Vintage.

Solnit, Rebecca. 2002. As Eve Said to the Serpent. On Landscape, Gender, and Art. Athens: University of Georgia Press.

Villarmea Álvarez, Iván. 2015. Documenting Cityscapes - Urban Change in Contemporary Non-Fiction Film. Nova Iorque: Columbia University Press.

\section{FILMOGRAFIA}

A Vida Provisória. [longa-metragem] Dir. Maurício Gomes Leite. Tekla Filmes/Saga Filmes/Luiz Carlos Barreto Produções Cinematográficas ET al., Brasil, 1968. 100mins.

Apocalypse Now [longa-metragem] Dir. Francis Ford Coppola. Omni Zoetrope ET al., U.S.A. et al., 1979. 153mins.

El botón de nácar [longa-metragem] Dir. Patricio Guzmán. Renate Sasche Productora, Chile/Francia, 2015. 1h22min.

Las aguas del olvido [curta-metragem] Dir. Jonathan Perel, Producción Jonathan Perel, Argentina, 2013. 9min.

Los durmientes. [Videotríptico HD, sonido, estéreo] Dir. Enrique Ramírez. Galería Michel Rein, Chile/Francia, 2014. 15 min.

Nazaré [longa-metragem] Dir. Manuel Guimarães. Pró-Filmes, Portugal, 1952. 81 mins.

Saltimbancos [longa-metragem] Dir. Manuel Guimarães. Lisboa Filme, Portugal, 1951. 98 mins.

Seopyeonje (서편제) [longa-metragem] Dir. Im Kwon-taek. Lee Taewon et al., South Korea et al., 1993. 112mins.

Sin Peso [curta-metragem] Dir. Cao Guimarães. Brasil, 2007. 7 min.

Sorcerer [longa-metragem] Dir. William Friedkin. Film Properties International N.V. et al., U.S.A. et al., 1977. 121mins. 
Ten Skies [longa-metragem] Dir. James Benning. EUA, 2004. 109 min.

The Searchers [longa-metragem] Dir. John Ford. C.V. Whitney Pictures et al., U.S.A. et al., 1956. 119mins.

The Shout [longa-metragem] Dir. Jerzy Skolimowski. Recorded Picture Company et al., U.K. et al., 1978. 86mins.

Vidas sem Rumo [longa-metragem]. Dir. Manuel Guimarães. PróFilmes, Portugal, 1956. 76 mins. 